\title{
Analysis of three-dimensional imaging findings and clinical symptoms in patients with temporomandibular joint disorders
}

\author{
Kug Jin Jeon^, Chena Lee^, Yoon Joo Choi^, Sang-Sun Han^ \\ Department of Oral and Maxillofacial Radiology, Yonsei University College of Dentistry, Seoul, Republic of Korea \\ Correspondence to: Sang-Sun Han, DDS, PhD. Department of Oral and Maxillofacial Radiology, Yonsei University College of Dentistry, 50-1 Yonsei- \\ ro Seodaemun-gu, Seoul, Korea. Email: sshan@yuhs.ac.
}

Background: The purpose of this study was to analyze cone-beam computed tomography (CBCT) and magnetic resonance imaging (MRI) findings in temporomandibular joint disorder (TMD) patients and to comprehensively assess the relationships between these imaging findings and clinical symptoms.

Methods: A total of 754 temporomandibular joints (TMJs) in 377 patients with clinical symptoms of TMD who underwent both CBCT and MRI examinations were retrospectively reviewed. Clinical symptoms included TMJ pain, TMJ sound, and limitation of mouth opening. Oral radiologists evaluated osseous changes of the condylar head on CBCT, as well as the disc configuration, internal derangement, and joint effusion on MRI. The frequency of CBCT and MRI findings and the mean and standard deviation of age were analyzed. Logistic regression analysis was used to identify associations between these imaging findings and clinical symptoms using SPSS version 25.0 for Windows (IBM Corp., Armonk, NY, USA). The model fit was evaluated using the Hosmer and Lemeshow test.

Results: TMD patients consisted of 294 females and 83 males, and the age group of 20-39 accounted for $47.2 \%$ of the patients. Normal findings regarding osseous changes of the condylar head on CBCT were found in $65.1 \%$ of the patients. On MRI, a change in disc configuration was found in $54.9 \%$ of the patients, internal derangement in $62.6 \%$, and joint effusion in $46.0 \%$. TMJ pain was significantly associated with sclerosis [odds ratio (OR): 3.81], disc displacement without reduction (DDWOR) (OR: 3.22), grade 2 joint effusion (OR: 2.33), and grade 3 joint effusion (OR: 5.54). TMJ sound was significantly associated with disc displacement with reduction (DDWR) (OR: 3.04), DDWOR (OR: 2.50), grade 2 joint effusion (OR: 2.37), and grade 3 joint effusion (OR: 3.23). Limitation of mouth opening was significantly associated with flattened disc configuration (OR: 2.08), folded disc configuration (OR: 2.30), and grade 3 joint effusion (OR: 2.85).

Conclusions: CBCT findings had little to do with clinical symptoms. In contrast, MRI findings, including disc configuration, internal derangement, and joint effusion, were associated with clinical symptoms. These results suggest that MRI should be recommended over CBCT for the proper diagnosis of TMD patients.

Keywords: Cone-beam computed tomography (CBCT); magnetic resonance imaging (MRI); temporomandibular joint; temporomandibular joint disorders (TMD); three-dimensional image

Submitted Jul 13, 2020. Accepted for publication Dec 15, 2020.

doi: 10.21037/qims-20-857

View this article at: http://dx.doi.org/10.21037/qims-20-857

^ ORCID: Kug Jin Jeon, 0000-0002-5862-2975; Chena Lee, 0000-0002-8943-4192; Yoon Joo Choi, 0000-0001-9225-3889; Sang-Sun Han, 0000$0003-1775-7862$ 


\section{Introduction}

The temporomandibular joint (TMJ), where the mandible articulates with the temporal bone of the cranium, is one of the most complex parts of the body. It must be biomechanically sound to withstand the high mechanical loads that occur during functioning, and it is constantly loaded even when not functioning (1). When the TMJ cannot tolerate these loads, a temporomandibular joint disorder (TMD) occurs. TMD is a major cause of nondental pain in the orofacial area (2). The TMJ consists of extracapsular components (such as capsules, ligaments, vessels, and nerves) and intracapsular components. Its intracapsular components can be divided into osseous components such as the mandibular condyle, glenoid (mandibular) fossa, and articular eminence, and soft tissue components such as the TMJ disc and disc attachment (1). Conventional radiography is insufficient for the diagnosis of TMD; therefore, the use of specialized imaging modalities such as cone-beam computed tomography (CBCT), computed tomography (CT), and magnetic resonance imaging (MRI) has gradually increased. CBCT is the standard imaging modality of choice for assessing degenerative bone changes of the TMJ, such as flattening, erosion, osteophytes, subchondral sclerosis, and subchondral cysts (3-6). CT can be used for the same purpose, but since the radiation dose is higher, CBCT should be used, which gives the patient the same information with less radiation exposure (1). MRI is known to be useful for evaluating discs and soft tissues (7). Conventional MRI has limitations in obtaining optimal bone images, and a study using the zeroTE sequence to compensate for these limitations have been reported (8). MRI is absolutely contraindicated in patients with ferromagnetic vascular clips and pacemakers, and imaging may be difficult if the patient experiences claustrophobia, which occurs in 1-15\% of patients undergoing MRI (9).

TMD exhibits a variety of clinical signs and symptoms, the most important of which are pain or tenderness in the TMJ area, sounds such as clicking, popping, or crepitus during jaw movement, and lock or limitation in mouth opening. Minor symptoms may include headache, ear pain, tinnitus, depression, and vertigo. Previous research has investigated associations between clinical symptoms and degenerative changes on CBCT (10-13). According to Arayasantiparb et al., crepitation had a statistically significant correlation with CBCT findings such as sclerosis, subchondral cyst, erosion, and osteophyte formation (10).
Palconet et al. reported that there was no correlation between osseous changes and clinical symptoms (12). Several studies have explored the relationships between MRI findings and clinical symptoms, especially pain (14-23). Murakami et al. evaluated the presence of bilateral effusion in patients with unilateral TMJ pain and reported that effusion was not correlated with pain (22). Takahara et al. reported that disc displacement without reduction (DDWOR) and increased joint effusion were associated with pain (23). Hosgor et al. concluded that marked joint effusion showed a statistically significant association with pain (21). Most previous studies in patients with TMD used one imaging modality (CBCT or MRI), and clinical symptoms have mostly focused on pain.

The purpose of this study was to analyze the relationships between three-dimensional imaging findings (CBCT and MRI) and clinical symptoms in patients with TMD.

\section{Methods}

\section{Subjects}

This study included 754 joints in 377 patients (age range, $10-82$ years; mean age, $33.3 \pm 16.23$ years) with clinical symptoms of TMD who underwent both CBCT and MRI examinations from January 2019 to December 2019 at Yonsei University Dental Hospital. This study was approved by the Institutional Review Board (IRB) of Yonsei University Dental Hospital (IRB no. 2-2019-0077) and was performed in accordance with all relevant guidelines and regulations. The requirement for patient consent was waived by the IRB of Yonsei University Dental Hospital because of the retrospective nature of the study.

Patients with both CBCT and MRI taken within a month were included. Patients who had received TMD treatment for more than 2 months and those with a TMJ fracture, cyst, tumor, or odontogenic inflammation such as osteomyelitis that could affect the TMJ were excluded (Figure 1).

Clinical diagnoses were made according to the Diagnostic Criteria for Temporomandibular Disorders (DC/TMD) (24). Clinical symptoms were classified into TMJ pain, TMJ sound (clicking, popping, or crepitus), and limitation of mouth opening (assisted opening $<40 \mathrm{~mm}$ ), as these are the three symptoms that TMD patients most frequently complain of (25). The category of TMJ pain excluded pain of muscular origin, such as pain in response to palpation of the temporalis or masseter muscle, and pain 


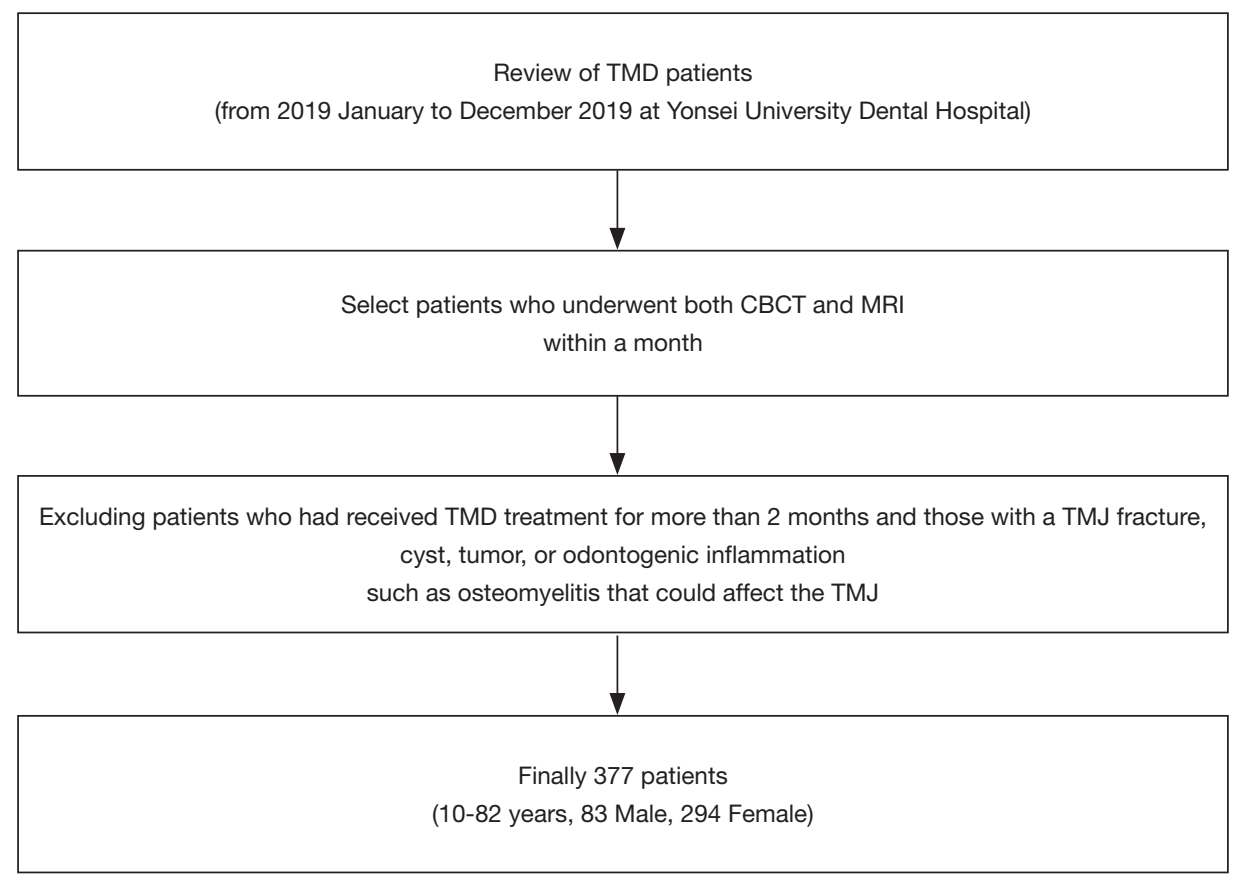

Figure 1 Flowchart of subject selection.

occurring upon provocation testing of masticatory muscles. If one patient had multiple symptoms of pain, sound, and limitation of mouth opening, all symptoms were recorded. Four oral and maxillofacial radiologists with over 10 years of experience evaluated the CBCT and MRI scans on monitors (Totoku Electric Co., Nagano, Japan). All imaging diagnoses were confirmed by at least two radiologists.

\section{CBCT evaluation}

The CBCT examinations were performed using an Alphard 3030 device (Asahi Roentgen Ind., Co. Ltd, Kyoto, Japan) with the following parameters: $80 \mathrm{kVp}, 8 \mathrm{~mA}, 17$ seconds, FOV $154 \times 154 \mathrm{~mm}$, voxel size $0.3 \mathrm{~mm}$. Using the OnDemand 3D software (Cybermed, Seoul, Korea), sagittal views and coronal views reconstructed with a $1 \mathrm{~mm}$ slice thickness along the long axis of the mandibular condyle were obtained.

Osseous changes of the condyle were classified according to Alexiou et al. (26) as normal, subchondral sclerosis (increased bony density including generalized sclerosis), flattening (flat bony contour), erosion (an interruption or absence of the cortical lining), osteophyte (marginal bony outgrowth), or combined (combination of two or more osseous changes) (Figure 2). Subcondral cysts (round or oval shaped osteolytic areas beneath the cortical bone) were not included.

\section{MRI evaluation}

MRI scans of the TMJ were acquired using a $3.0 \mathrm{~T}$ scanner (Pioneer; GE Healthcare, Waukesha, WI, USA) with a 16-channel flex large coil. Sagittal proton densityweighted images in the closed-mouth and open-mouth positions were obtained with the following parameters: TE/ TR, 50/2084 ms; bandwidth, $41.67 \mathrm{kHz}$; NEX, 1.5; FOV, $130 \times 130 \mathrm{~mm}$; slice thickness, $2.5 \mathrm{~mm}$; and scan time, $2 \mathrm{~min}$ 14 sec. Coronal proton density-weighted images in the closed-mouth position were obtained with the following parameters: TE/TR, 50/1500 ms; bandwidth, $41.67 \mathrm{kHz}$; NEX, 2; FOV, 130×130 mm; slice thickness, $2.5 \mathrm{~mm}$; and scan time, 2 min $3 \mathrm{sec}$. Sagittal T2-weighted images in the closed-mouth and open-mouth positions were obtained with the following parameters: TE/TR, 80/3088 ms; bandwidth, $25.00 \mathrm{kHz}$; NEX, 1.5; FOV, 130×130 mm; slice thickness, $2.5 \mathrm{~mm}$; and scan time, $2 \mathrm{~min} 16 \mathrm{sec}$.

Disc configuration, internal derangement, and joint effusion were evaluated on MRI scans. Disc configuration was classified according to Arayasantiparb et al. (27) as biconcave (disc with thick anterior and posterior bands and 

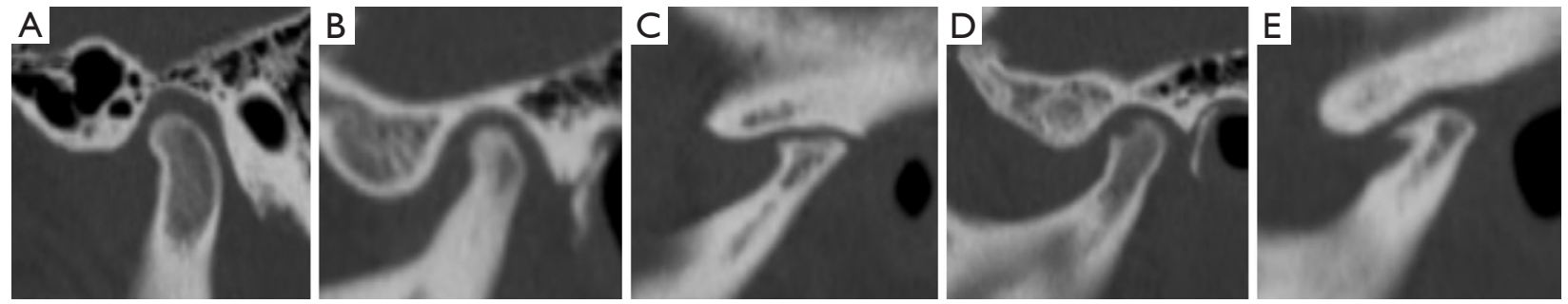

Figure 2 Osseous changes of the condylar head on CBCT were classified as follows: (A) normal, (B) sclerosis, (C) flattening, (D) erosion, (E) osteophyte.
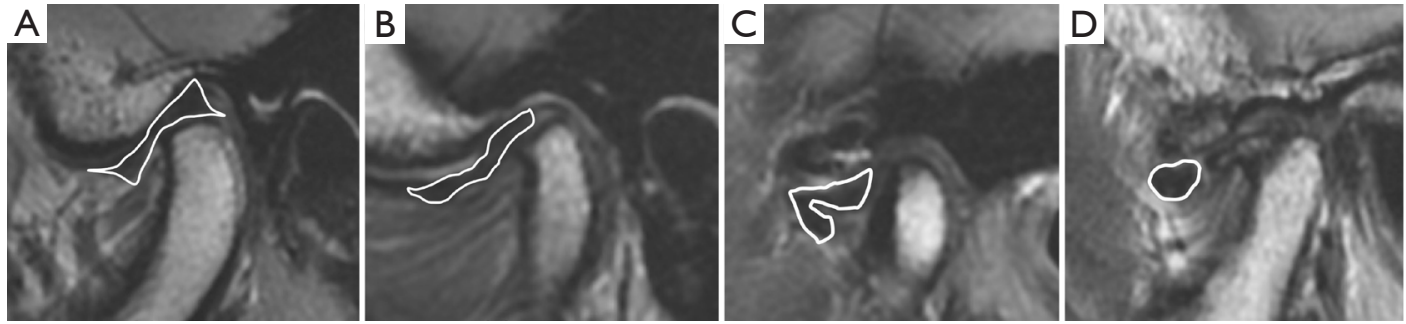

Figure 3 Disc configuration on MRI was classified as follows: (A) biconcave, (B) flattened, (C) folded, (D) convex.
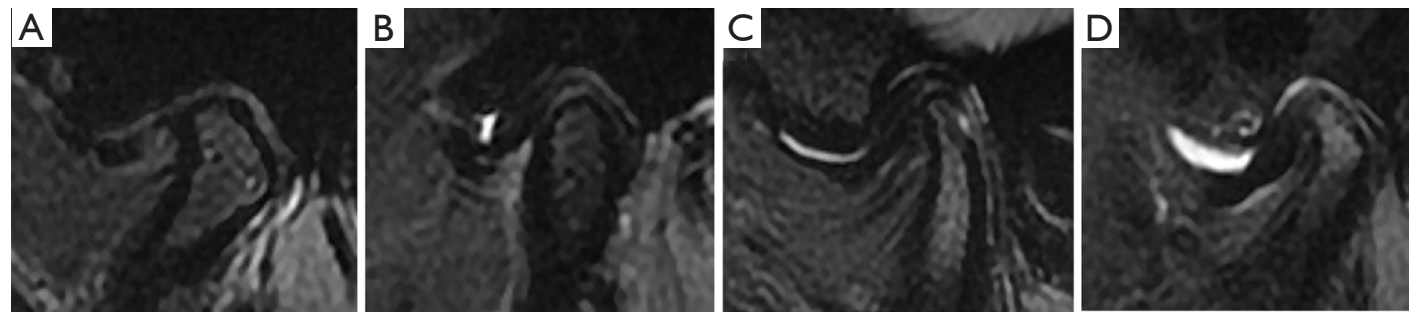

Figure 4 Joint effusion was classified on T2-weighted images: (A) grade 0, (B) grade 1, (C) grade 2, (D) grade 3.

a thin intermediate zone), flattened (disc with the same thickness of the anterior band, intermediate zone, and posterior band), folded (disc with any folded portion), or convex (disc with convex upper and lower surfaces) in the closed-mouth position (Figure 3).

Internal derangement was classified according to Koh et al. (28) as normal (posterior band located above the apex of the condylar head in the closed-mouth position and thin intermediate zone located between the condyle and the articular eminence in the open-mouth position), disc displacement with reduction (DDWR; posterior band located anterior to the condylar head in the closed-mouth position, but with a normal disc-condyle relationship in the open-mouth position), or disc displacement without reduction (DDWOR; posterior band positioned anterior to the condyle in both the closed-mouth and open-mouth positions).

Joint effusion was classified into four degrees based on previous reports $(29,30)$ as follows: grade 0 (no bright T2 signal intensity in the joint space), grade 1 (dots or lines of bright $\mathrm{T} 2$ signal intensity along the articular surface), grade 2 (bands of bright T2 signal intensity), and grade 3 (collection with pooling of bright $\mathrm{T} 2$ signal intensity in the joint space) (Figure 4).

\section{Data analysis}

The frequency of CBCT and MRI findings and the mean and standard deviation of age were analyzed. We conducted inferential statistical analyses of the relationships of CBCT and MRI findings with clinical symptoms using logistic regression analysis. Statistical analyses were performed 
with SPSS version 25.0 for Windows (IBM Corp., Armonk, NY, USA). Osseous changes, disc configuration, internal derangement, and joint effusion were adjusted, and the model fit of the logistic regression analysis was evaluated using the Hosmer and Lemeshow test.

\section{Results}

The 377 TMD patients comprised 294 females and 83 males. The most common age group was 20-29 years (28.6\%), followed by $30-39$ years (18.6\%) (Table 1). There were 177 patients $(46.9 \%)$ with bilateral clinical symptoms and 200 patients $(53.1 \%)$ with unilateral clinical symptoms. The frequency of clinical symptoms in the 754 joints was as follows: TMJ pain (57.8\%), TMJ sound (53.2\%), and limitation of mouth opening (22.9\%).

Table 2 shows osseous changes of the condylar head on CBCT. Normal findings were present regarding osseous changes of the condylar head in $65.1 \%$ of patients. Table 3 shows the MRI findings, including disc configuration,

Table 1 Age distribution of patients

\begin{tabular}{lccc}
\hline Age (in years) & Male & Female & Total $(\%)$ \\
\hline $10-19$ & 20 & 36 & $56(14.9)$ \\
$20-29$ & 35 & 73 & $108(28.6)$ \\
$30-39$ & 11 & 59 & $70(18.6)$ \\
$40-49$ & 5 & 43 & $48(12.7)$ \\
$50-59$ & 5 & 48 & $53(14.1)$ \\
$60-69$ & 5 & 26 & $31(8.2)$ \\
$\geq 70$ & 2 & 9 & $11(2.9)$ \\
Total & 83 & 294 & $377(100.0)$ \\
\hline
\end{tabular}

internal derangement, and joint effusion. Changes in disc configuration (flattened, folded, or convex) were present in $54.9 \%$ of patients, internal derangement (DDWR or DDWOR) in $62.6 \%$, and joint effusion (grade $1,2,3$ ) in $46.0 \%$.

Table 4 shows odds ratios (ORs) of CBCT findings and MRI findings according to TMD symptoms. TMJ pain was significantly associated with sclerosis (OR: $3.81, \mathrm{P}=0.001$ ), DDWOR (OR: $3.22, \mathrm{P}=0.001$ ), grade 2 joint effusion (OR: 2.33, $\mathrm{P}=0.001$ ), and grade 3 joint effusion (OR: $5.54, \mathrm{P}<0.001)$. However, a convex disc configuration was negatively associated with TMJ pain (OR: $0.43, \mathrm{P}=0.04)$. TMJ sound was significantly associated with DDWR (OR: 3.04, $\mathrm{P}<0.001$ ), DDWOR (OR: 2.50, $\mathrm{P}=0.005$ ), grade 2 joint effusion (OR: 2.37, $\mathrm{P}<0.001$ ), and grade 3 joint effusion (OR: 3.23, $\mathrm{P}<0.001)$. A convex disc configuration was negatively associated with TMJ sound (OR: 0.36, $\mathrm{P}=0.008)$. Limitation of mouth opening was significantly associated with a flattened disc configuration (OR: 2.08, $\mathrm{P}=0.029)$, folded disc configuration (OR: 2.30, $\mathrm{P}=0.032$ ), and grade 3 joint effusion (OR: $2.85, \mathrm{P}=0.001$ ).

\section{Discussion}

TMD is known to occur commonly in women 20 to 40 years old (31-33), but it is gradually becoming more common and occurring at younger ages. This study found that female patients accounted for a 3.5 times higher proportion of TMD patients than male patients. The most common age group of TMD patients was 20-39 years old, followed by $10-19$ years old.

The causes of TMD are very diverse and complex, and include disc, masticatory muscle, bone disease (osteoarthritis), TMJ-related ligament, retrodiscal tissue, and synovial membrane problems. The clinical symptoms

Table 2 Osseous changes of the condylar head on CBCT

\begin{tabular}{lccc}
\hline Osseous changes & Male $($ mean age \pm SD) & Female (mean age \pm SD) & Total (\%) \\
\hline Normal & $123(30.07 \pm 14.16)$ & $368(35.96 \pm 15.92)$ & $491(65.1)$ \\
Sclerosis & $12(26.33 \pm 12.77)$ & $35(32.51 \pm 14.15)$ & $47(6.2)$ \\
Flattening & $7(25.57 \pm 14.73)$ & $46(41.89 \pm 15.19)$ & $53(7.0)$ \\
Erosion & $12(26.00 \pm 16.26)$ & $43(39.67 \pm 16.03)$ & $55(7.3)$ \\
Osteophyte & $1(73.00)$ & $10(52.40 \pm 14.30)$ & $11(1.5)$ \\
Combined & $11(40.82 \pm 18.17)$ & $86(46.74 \pm 16.36)$ & $97(12.9)$ \\
\hline
\end{tabular}

CBCT, cone-beam computed tomography; SD, standard deviation. 
Table 3 Disc configuration, internal derangement and joint effusion on MRI

\begin{tabular}{|c|c|c|c|}
\hline & Male (mean age $\pm \mathrm{SD}$ ) & Female (mean age \pm SD) & Total (\%) \\
\hline Biconcave & $88(32.01 \pm 15.00)$ & $252(37.74 \pm 16.84)$ & $340(45.1)$ \\
\hline Flattened & $49(27.39 \pm 12.70)$ & $125(36.91 \pm 15.78)$ & $174(23.1)$ \\
\hline Folded & $22(23.55 \pm 10.39)$ & $145(35.59 \pm 14.99)$ & $167(22.1)$ \\
\hline \multicolumn{4}{|c|}{ Internal derangement } \\
\hline Normal & $76(33.51 \pm 15.22)$ & $206(39.35 \pm 16.64)$ & $282(37.4)$ \\
\hline DDWR & $60(27.13 \pm 13.41)$ & $156(35.29 \pm 15.62)$ & $216(28.6)$ \\
\hline DDWOR & $30(28.43 \pm 16.54)$ & $226(39.54 \pm 16.46)$ & $256(34.0)$ \\
\hline Grade 1 & $28(27.21 \pm 14.23)$ & $103(35.48 \pm 15.42)$ & $131(17.4)$ \\
\hline Grade 2 & $30(28.47 \pm 16.38)$ & $111(37.84 \pm 14.78)$ & $141(18.7)$ \\
\hline Grade 3 & $11(33.46 \pm 17.13)$ & $64(38.33 \pm 18.51)$ & $75(9.9)$ \\
\hline
\end{tabular}

DDWR, disc displacement with reduction; DDWOR, disc displacement without reduction; MRI, magnetic resonance imaging; SD, standard deviation.

of TMD are likewise quite diverse, with pain, sound, and limitation of mouth opening predominating. In TMD, pain can be divided into TMJ pain (arthritic pain, capsular pain, retrodiscal pain, ligamentous pain) and/or masticatory muscle pain (myalgia, myofascial pain, local muscle soreness, myospasms) (24). In some patients with TMD, peripheral mechanisms contribute to pain, but there is a poor correlation between the severity of pain and evidence of definite tissue pathology (34). It is thought that psychosocial stress contributes to pain. Sound is caused by disc displacement and osteoarthritis (5). Limited mouth opening is caused by disc displacement, muscle contracture, and pain.

In the past, plain images such as panoramic radiography and transcranial, Towne, submentovertex, and lateral tomographic projections were used, but the demand for special modalities such as CBCT, CT, and MRI is increasing in order to evaluate tissue morphology and its spatial relationships more accurately (1). CBCT and CT show the osseous component comprehensively and can be used to analyze asymmetry, growth change (1). MRI shows the location and condition of soft tissue components, including the disc and its attachments, as well as the presence of joint effusion, soft tissue neoplasms, or tumor-like lesions (1).

On CBCT, $65.1 \%$ of TMD patients had no osseous changes of the condylar head. This is because they had no problems involving bone disease, or because osseous changes occur in the late stage even in cases with internal derangement (35). In the patients with osseous changes, a combination of two or more changes was the most common finding, while osteophytes, which occur at a later stage of bone change, were the least common. On MRI, changes in disc configuration and internal derangement appeared in $50 \%$ or more of cases, and joint effusion also appeared in almost half of the patients. Some joints may not have shown changes on MRI because the initial changes in the synovial membrane can only be detected by biopsy and arthroscopy, and are only displayed on radiographs after changes in the articular tissue $(36,37)$. In some joints without osseous changes on CBCT and abnormal MRI findings, the TMD is considered to be of muscular origin. Pain of muscular origin was excluded according to the DC/TMD, but it was clinically difficult to definitively distinguish muscle pain from TMJ pain.

In the analysis of the clinical symptoms of TMD and three-dimensional imaging findings, CBCT findings were associated only with TMJ pain, and MRI findings were associated with all clinical symptoms.

Sclerosis was the only osseous change on CBCT that showed an association with TMJ pain. Pain was 
Table 4 Odds ratios for CBCT and MRI findings according to temporomandibular joint symptoms

\begin{tabular}{|c|c|c|c|c|c|c|c|c|c|}
\hline & \multicolumn{3}{|c|}{ TMJ pain } & \multicolumn{3}{|c|}{ TMJ sound } & \multicolumn{3}{|c|}{ Limitation of mouth opening } \\
\hline \multicolumn{10}{|l|}{ СВCT finding } \\
\hline \multicolumn{10}{|c|}{ Osseous change } \\
\hline Normal & 1.00 & & & 1.00 & & & 1.00 & & \\
\hline Flattening & 0.99 & $0.53-1.87$ & 0.984 & 0.94 & $0.50-1.77$ & 0.852 & 1.28 & $0.62-2.65$ & 0.499 \\
\hline Erosion & 1.98 & $0.97-4.08$ & 0.062 & 1.36 & $0.70-2.63$ & 0.363 & 1.49 & $0.75-2.95$ & 0.250 \\
\hline Osteophyte & 1.66 & $0.40-6.93$ & 0.489 & 1.14 & $0.31-4.19$ & 0.844 & 1.61 & $0.41-6.34$ & 0.494 \\
\hline Combined & 1.62 & $0.88-2.97$ & 0.122 & 1.17 & $0.67-2.04$ & 0.576 & 1.77 & $1.00-3.15$ & 0.051 \\
\hline Biconcave & 1.00 & & & 1.00 & & & 1.00 & & \\
\hline Flattened & 0.73 & $0.43-1.23$ & 0.236 & 0.64 & $0.38-1.08$ & 0.097 & 2.08 & $1.08-4.03$ & $0.029^{*}$ \\
\hline Folded & 0.53 & $0.27-1.04$ & 0.064 & 0.73 & $0.38-1.40$ & 0.349 & 2.30 & $1.08-4.90$ & $0.032^{*}$ \\
\hline Convex & 0.43 & $0.19-0.97$ & $0.040^{*}$ & 0.36 & $0.17-0.76$ & $0.008^{\star}$ & 1.33 & $0.55-3.20$ & 0.525 \\
\hline \multicolumn{10}{|l|}{$\begin{array}{l}\text { Internal } \\
\text { derangement }\end{array}$} \\
\hline Normal & 1.00 & & & 1.00 & & & 1.00 & & \\
\hline DDWR & 1.23 & $0.75-2.03$ & 0.413 & 3.04 & $1.84-5.02$ & $<0.001^{*}$ & 0.73 & $0.37-1.45$ & 0.375 \\
\hline Grade 3 & 5.54 & $2.61-11.76$ & $<0.001^{*}$ & 3.23 & $1.74-6.02$ & $<0.001^{*}$ & 2.85 & $1.58-5.14$ & $0.001^{*}$ \\
\hline
\end{tabular}

$\mathrm{Cl}$, confidence interval; DDWR, disc displacement with reduction; DDWOR, disc displacement without reduction; OR, odds ratio analyzed by logistic regression analysis; ${ }^{*} \mathrm{P}<0.05$. Adjusted for osseous change, disc configuration, internal derangement and joint effusion. Pain (Hosmer and Lemeshow test; $\mathrm{P}=0.797$ ); sound (Hosmer and Lemeshow test; $\mathrm{P}=0.888$ ); limitation (Hosmer and Lemeshow test; $\mathrm{P}=0.562$ ).

more likely to occur when erosion was present, but this tendency was not statistically significant. Some previous studies have reported a relationship between erosion and pain $(11,38,39)$, while other studies have failed to find a relationship between pain and osseous changes (12,40-42). However, in our study, sclerosis was associated with pain. This discrepancy can be explained by the fact that sclerosis occurs during the remodeling process, which is an adaptive response of the joints (43). In other words, TMD is a chronic disease, and the osseous change shown in a single image does not directly reflect the patient's status over time. In order to establish accurate correlations between clinical symptoms and osseous changes on CBCT, studies that track bony change patterns over time, rather than at one time point, are needed. Among the MRI findings, TMJ pain was associated with DDWOR, grade 2 joint effusion, and grade 3 joint effusion, and was negatively associated with a convex disc configuration. A relationship between DDWOR and pain was reported by previous studies $(20,23)$. DDWOR and pain are related because anterior displacement of the 
disc causes an overload of the retrodiscal tissue, which in turn leads to increased degeneration and inflammation of the joints due to an increase in free radicals and nitric oxide production in this area $(44,45)$. Since pain is caused by posterior ligament injury, DDWR was more likely to cause pain, but this tendency was not statistically significant. Joint effusion has been proposed as fluid that shows intra-articular inflammation (46). The exact cause of TMJ effusion is somewhat unclear, but it appears to be related to a dysfunctional relationship between the mandibular condyle and disc (46). This misalignment results in deterioration and wear of the articular cartilage and disc surface, leading in turn to the release of proinflammatory cytokines including tumor necrosis factoralpha, nitric oxide, bradykinin, interleukin (IL)-6, IL1 , IL-8, and leukotriene B4 $(47,48)$. These inflammatory cytokines promote joint destruction and produce a painful inflammatory exudate around the joint. Some studies have reported that joint effusion was statistically significantly associated with pain $(20,21,23)$. However, Murakami et al. reported that effusion was not correlated with pain (22). It is thought that moderate to severe effusion is associated with pain. The convex disc configuration appears mainly in DDWOR, and pain and DDWOR showed positive correlations, whereas pain and the convex disc form showed a negative correlation; additional research is needed to clarify these relationships.

Sound was not associated with CBCT findings. Among the MRI findings, sound was associated with DDWR, DDWOR, grade 2 joint effusion, and grade 3 joint effusion, and was negatively associated with convex disc configuration. A previous study reported that clicking occurs in joints with DDWR, DDWOR, and arthritis, and that crepitation occurs in joints with perforation and arthritis (49). DDWOR is a late stage of internal derangement, and it is thought to be related to sound due to an increased risk of osteoarthritis. Consistent with our findings, Matsubara et $a l$. reported that grade 2 and 3 joint effusion was associated with sound (20). The inflammatory cytokines present in effusion promote joint destruction and induce arthritis, which is thought to produce sound. A convex form was negatively associated with TMJ sound. This is thought to be because a convex disc configuration appears in the late stage of internal derangement, and it is difficult for the condyle to make a sound beyond the clustered disc.

Limitation of mouth opening was not associated with any CBCT findings. Among the MRI findings, limitation of mouth opening was associated with a flattened and folded disc configuration and grade 3 joint effusion. Regarding the CBCT findings, the likelihood of limitation of mouth opening increased in the presence of osseous changes (including sclerosis, erosion, osteophytes, or combined); however, these relationships were not statistically significant. Regarding the fact that a flattened and folded disc configuration is associated with limited mouth opening, it is considered that the mandibular condyle locks into the deformed disc with the mouth open, resulting in limitation of mouth opening. A possible explanation for the lack of statistical significance may be that the convex disc configuration occurs in the late stage of internal derangement, when the disc may have more anterior displacement than at the time of $40-\mathrm{mm}$ mouth opening. The relationship between joint effusion and limitation of mouth opening is mediated by the pain caused by effusion.

The main limitation of this study is that since it was a retrospective study, it was difficult to clearly classify complex clinical symptoms, and subchondral cysts were not included in osseous changes. Further studies require planned and comprehensive prospective research and time tracking studies, and analyses of the relationships between a greater number of convex discs and pain are needed.

\section{Conclusions}

Clinicians should evaluate the clinical symptoms of patients with TMD and perform CBCT or MRI depending on their symptoms. MRI findings including disc configuration, disc position, and joint effusion were more closely related to clinical symptoms than CBCT findings. If one is not sure which imaging technique is suitable, MRI is recommended as a higher-priority imaging modality over CBCT for the proper diagnosis of TMD.

\section{Acknowledgments}

Funding: This work was supported by the Medical Device Technology Development Program (grant number 20006098), "Development of soft-tissue diagnostic CT with $31 \mathrm{p} / \mathrm{mm}$ resolution using multi-source and curved FPD" funded by the Ministry of Trade, Industry and Energy (MOTIE, Korea).

\section{Footnote}

Conflicts of Interest: All authors have completed the ICMJE uniform disclosure form (available at http://dx.doi. 
org/10.21037/qims-20-857). The authors have no conflicts of interest to declare.

Ethical Statement: This study was reviewed and approved by the Institutional Review Board of Yonsei University Dental Hospital (No. 2-2019-0077) and was performed in accordance with all relevant guidelines and regulations. The requirement for patient consent was waived by the IRB of Yonsei University Dental Hospital because of the retrospective nature of the study.

Open Access Statement: This is an Open Access article distributed in accordance with the Creative Commons Attribution-NonCommercial-NoDerivs 4.0 International License (CC BY-NC-ND 4.0), which permits the noncommercial replication and distribution of the article with the strict proviso that no changes or edits are made and the original work is properly cited (including links to both the formal publication through the relevant DOI and the license). See: https://creativecommons.org/licenses/by-nc-nd/4.0/.

\section{References}

1. Tamimi D, Kocasarac HD, Mardini S. Imaging of the Temporomandibular Joint. Semin Roentgenol 2019;54:282-301.

2. de Leeuw R (ed). Orofacial Pain: Guidelines for Assessment, Diagnosis, and Management (4th edn). Hanover park, IL. Quintessence Publishing Co, Inc, 2008.

3. Shetty US, Burde KN, Naikmasur VG, Sattur AP. Assessment of condylar changes in patients with temporomandibular joint pain using digital volumetric tomography. Radiol Res Pract 2014;2014:106059.

4. Zain-Alabdeen EH, Alsadhan RI. A comparative study of accuracy of detection of surface osseous changes in the temporomandibular joint using multidetector $\mathrm{CT}$ and cone beam CT. Dentomaxillofac Radiol 2012;41:185-91.

5. dos Anjos Pontual ML, Freire JS, Barbosa JM, Frazao MA, dos Anjos Pontual A. Evaluation of bone changes in the temporomandibular joint using cone beam CT. Dentomaxillofac Radiol 2012;41:24-9.

6. Alexiou K, Stamatakis HC, Tsiklakis K. Evaluation of the severity of temporomandibular joint osteoarthritic changes related to age using cone beam computed tomography. Dentomaxillofac Radiol 2009;38:141-7.

7. Tasaki MM, Westesson PL. Temporomandibular joint: Diagnostic accuracy with sagittal and coronal MR imaging. Radiology 1993;186:723-9.
8. Lee C, Jeon KJ, Han S-S, Kim YH, Choi YJ, Lee A, Choi JH. CT-like MRI using the zero-TE technique for osseous changes of the TMJ. Dentomaxillofac Radiol 2020;49:20190272.

9. Dill T. Contraindications to magnetic resonance imaging: Non-invasive imaging. Heart 2008;94:943-8.

10. Arayasantiparb R, Mitrirattanakul S, Kunasarapun P, Chutimataewin H, Netnoparat P, Sae-Heng W. Association of radiographic and clinical findings in patients with temporomandibular joints osseous alteration. Clin Oral Investig 2020;24:221-7.

11. Emshoff R, Bertram F, Schnabl D, Stigler R, Steinmassl $\mathrm{O}$, Rudisch A. Condylar erosion in patients with chronic temporomandibular joint arthralgia: A Cone-Beam Computed Tomography Study. J Oral Maxillofac Surg 2016;74:1343.e1-8.

12. Palconet G, Ludlow JB, Tyndall DA, Lim PF. Correlating cone beam CT results with temporomandibular joint pain of osteoarthritic origin. Dentomaxillofac Radiol 2012;41:126-30.

13. Derwich M, Mitus-Kenig M, Pawlowska E. Temporomandibular Joints' Morphology and Osteoarthritic Changes in Cone-Beam Computed Tomography Images in Patients with and without Reciprocal Clicking-A Case Control Study. Int J Environ Res Public Health 2020;17:3428.

14. Larheim TA, Westesson P, Sano T. Temporomandibular joint disk displacement: comparison in asymptomatic volunteers and patients. Radiology 2001;218:428-32.

15. Paesani D, Westesson PL, Hatala MP, Tallents RH, Brooks SL. Accuracy of clinical diagnosis for TMJ internal derangement and arthrosis. Oral Surg Oral Med Oral Pathol 1992;73:360-3.

16. Emshoff R, Innerhofer K, Rudisch A, Bertram S. Clinical versus magnetic resonance imaging findings with internal derangement of the temporomandibular joint: an evaluation of anterior disc displacement without reduction. J Oral Maxillofac Surg 2002;60:36-41.

17. Emshoff R, Brandlmaier I, Bertram S, Rudisch A. Relative odds of temporomandibular joint pain as a function of magnetic resonance imaging findings of internal derangement, osteoarthrosis, effusion, and bone marrow edema. Oral Surg Oral Med Oral Pathol Oral Radiol Endod 2003;95:437-45.

18. Emshoff R, Brandlmaier I, Bertram S, Rudisch A. Risk factors for temporomandibular joint pain in patients with disc displacement without reduction - a magnetic resonance imaging study. J Oral Rehabil 2003;30:537-43. 
19. Larheim TA, Westesson PL, Sano T. MR grading of temporomandibular joint fluid: association with disk displacement categories, condyle marrow abnormalities and pain. Int J Oral Maxillofac Surg 2001;30:104-12.

20. Matsubara R, Yanagi Y, Oki K, Hisatomi M, Santos KC, Bamgbose BO, Fujita M, Okada S, Minagi S, Asaumi J. Assessment of MRI findings and clinical symptoms in patients with temporomandibular joint disorders. Dentomaxillofac Radiol 2018;47:20170412.

21. Hosgor H. The relationship between temporomandibular joint effusion and pain in patients with internal derangement. J Craniomaxillofac Surg 2019;47:940-4.

22. Murakami K, Nishida M, Bessho K, Iizuka T, Tsuda Y, Konishi J. MRI evidence of high signal intensity and temporomandibular arthralgia and relating pain. Does the high signal correlate to the pain? Br J Oral Maxillofac Surg 1996;34:220-4.

23. Takahara N, Nakagawa S, Sumikura K, Kabasawa Y, Sakamoto I, Harada H. Association of Temporomandibular Joint Pain According to Magnetic Resonance Imaging Findings in Temporomandibular Disorder Patients. J Oral Maxillofac Surg 2017;75:1848-55.

24. Schiffman E, Ohrbach R, Truelove E, Look J, Anderson G, Goulet JP, List T, Svensson P, Gonzalez Y, Lobbezoo F, Michelotti A, Brooks SL, Ceusters W, Drangsholt M, Ettlin D, Gaul C, Goldberg LJ, Haythornthwaite JA, Hollender L, Jensen R, John MT, De Laat A, de Leeuw R, Maixner W, van der Meulen M, Murray GM, Nixdorf DR, Palla S, Petersson A, Pionchon P, Smith B, Visscher CM, Zakrzewska J, Dworkin SF. International RDC/ TMD Consortium Network, International association for Dental Research; Orofacial Pain Special Interest Group, International Association for the Study of Pain. Diagnostic Criteria for Temporomandibular Disorders (DC/TMD) for clinical and research applications: recommendations of the International RDC/TMD Consortium Network* and Orofacial Pain Special Interest Group. J Oral Facial Pain Headache 2014;28:6-27.

25. Helenius LM, Tervahartiala P, Helenius I, Al-Sukhun J, Kivisaari L, Suuronen R, Kautiainen H, Hallikainen D, Lindqvist C, Leirisalo-Repo M. Clinical, radiographic and MRI findings of the temporomandibular joint in patients with different rheumatic diseases. Int J Oral Maxillofac Surg 2006;35:983-9.

26. Alexiou K, Stamatakis H, Tsiklakis K. Evaluation of the severity of temporomandibular joint osteoarthritic changes related to age using cone beam computed tomography. Dentomaxillofac Radiol 2009;38:141-7.
27. Arayasantiparb R, Tsuchimochi M, Mitrirattanakul S. Transformation of temporomandibular joint disc configuration in internal derangement patients using magnetic resonance imaging. Oral Science International 2012;9:43-8.

28. Koh KJ, Park HN, Kim KA. Relationship between anterior disc displacement with/without reduction and effusion in temporomandibular disorder patients using magnetic resonance imaging. Imaging Sci Dent 2013;43:245-51.

29. Wänman A, Agerberg G. Mandibular dysfunction in adolescents. I. Prevalence of symptoms. Acta Odontol Scand 1986;44:47-54.

30. Shi Z, Guo C, Awad M. Hyaluronate for temporomandibular joint disorders. Cochrane Database Syst Rev 2003;1:CD002970.

31. Barros VM, Seraidarian PI, Côrtes MI, de Paula LV. The impact of orofacial pain on the quality of life of patients with temporomandibular disorder. J Orofac Pain 2009;23:28-37.

32. Tjakkes GH, Reinders JJ, Tenvergert EM, Stegenga B. TMD pain: The effect on health related quality of life and the influence of pain duration. Health Qual Life Outcomes 2010;8:46.

33. Solberg WK, Woo MW, Houston JB. Prevalence of mandibular dysfunction in young adults. J Am Dent Assoc 1979;98:25-34.

34. Cairns BE. Pathophysiology of TMD pain--basic mechanisms and their implications for pharmacotherapy. J Oral Rehabil 2010; 37:391-410.

35. Wilkes CH. Internal derangements of the temporomandibular joint. Pathologic variations. Arch Otolaryngol Head Neck Surg 1989;115:469-77.

36. Dijkgraaf LC, Spijkervet FK, de Bont LG. Arthroscopic findings in osteoarthritic temporomandibular joints. J Oral Maxillofac Surg 1999;57:255-68.

37. Stegenga B. Osteoarthritis of the temporomandibular joint organ and its relationship to disc displacement. J Orofac Pain 2001;15:193-205.

38. Cevidanes LH, Hajati AK, Paniagua B, Lim PF, Walker DG, Palconet G, Nackley AG, Styner M, Ludlow JB, Zhu $\mathrm{H}$, Phillips C. Quantification of condylar resorption in temporomandibular joint osteoarthritis. Oral Surg Oral Med Oral Pathol Oral Radiol Endod 2010;110:110-7.

39. Imanimoghaddam M, Madani AS, Talebzadeh MR, Bagherpour A, Alimohammadi M. The relationship between osseous changes of the temporomandibular joint and RDC/TMD groups in CBCT images. J Dent Mater Tech 2014;3:151-7. 
40. Wiese M, Svensson P, Bakke M, List T, Hintze H, Petersson A, Knutsson K, Wenzel A. Associations between temporomandibular joint symptoms, signs, and clinical diagnosis using the RDC/TMD and radiographic findings in temporomandibular joint tomograms. J Orofac Pain 2008;22:239-51.

41. Ohlmann B, Rammelsberg P, Henschel V, Kress B, Gabbert O, Schmitter M. Prediction of TMJ arthralgia according to clinical diagnosis and MRI findings. Int J Prosthodont 2006;19:333-8.

42. Larheim TA. Current trends in temporomandibular joint imaging. Oral Surg Oral Med Oral Pathol Oral Radiol Endod 1995;80:555-76.

43. Edwards R, Alsufyani N, Heo G, Flores-Mir C. The frequency and nature of incidental findings in large-field cone beam computed tomography scans of an orthodontic sample. Prog Orthod 2014;15:37.

44. Milam SB, Schmitz JP. Molecular biology of temporomandibular joint disorders: proposed mechanisms of disease. J Oral Maxillofac Surg 1995;53:1448-54.

45. Koca CG, Gümrükçü Z, Bilgir E. Does clinical findings correlate with magnetic resonance imaging (MRI) findings in patients with temporomandibular joint (TMJ) pain?

Cite this article as: Jeon KJ, Lee C, Choi YJ, Han SS. Analysis of three-dimensional imaging findings and clinical symptoms in patients with temporomandibular joint disorders. Quant Imaging Med Surg 2021;11(5):1921-1931. doi: 10.21037/qims20-857
A cross sectional study. Med Oral Patol Oral Cir Bucal 2020;25:e495-e501.

46. Segami N, Suzuki T, Sato J, Miyamaru M, Nishimura M, Yoshimura H. Does joint effusion on T2 magnetic resonance images reflect synovitis? Part 3. Comparison of histologic findings of arthroscopically obtained synovium in internal derangements of the temporomandibular joint. Oral Surg Oral Med Oral Pathol Oral Radiol Endod 2003;95:761-6.

47. Takahashi T, Kondoh T, Fukuda M, Yamazaki Y, Toyosaki T, Suzuki R. Proinflammatory cytokines detectable in synovial fluids from patients with temporomandibular disorders. Oral Surg Oral Med Oral Pathol Oral Radiol Endod 1998;85:135-41.

48. Suenaga S, Abeyama K, Hamasaki A, Mimura T, Noikura T. Temporomandibular disorders: relationship between joint pain and effusion and nitric oxide concentration in the joint fluid. Dentomaxillofac Radiol 2001;30:214-8.

49. Widmalm SE, Westesson PL, Brooks SL, Hatala MP, Paesani D. Temporomandibular joint sounds: correlation to joint structure in fresh autopsy specimens. Am J Orthod Dentofacial Orthop 1992;101:60-9. 